\title{
Assessment of the Genetic Diversity and Population Structure of Lotus Cultivars Grown in China by Amplified Fragment Length Polymorphism
}

\author{
Jie $\mathbf{F} \mathbf{u}^{1}$ \\ Key Laboratory of Aquatic Plant and Watershed Ecology, Wuhan Botanical Garden, Chinese \\ Academy of Sciences, Wuhan, Hubei 430074, China \\ Qiaoyan Xiang ${ }^{1}$ \\ Open Laboratory of Enhancement and Sustainable Use of Germplasm of Unique Agricultural \\ Resource Plants, Wuhan Botanical Garden, Chinese Academy of Sciences, Wuhan, Hubei 430074, \\ China \\ Xianbao Zeng \\ Lotus Center of East-lake Scenic Area, Wuhan, Hubei 430074, China
}

Mei Yang

Key Laboratory of Aquatic Plant and Watershed Ecology, Wuhan Botanical Garden, Chinese Academy of Sciences, Wuhan, Hubei 430074, China

\begin{abstract}
Ying Wang
Open Laboratory of Enhancement and Sustainable Use of Germplasm of Unique Agricultural

Resource Plants, Wuhan Botanical Garden, Chinese Academy of Sciences, Wuhan, Hubei 430074, China
\end{abstract}

Yanling Liu $^{2}$

Key Laboratory of Aquatic Plant and Watershed Ecology, Wuhan Botanical Garden, Chinese Academy of Sciences, Wuhan, Hubei 430074, China

\begin{abstract}
AdDITIONAL INDEX WORDs. Nelumbo, genetic variation, molecular marker
Abstract. To assess the genetic diversity among lotus (Nelumbo) accessions and evaluate the correlation between genetic variation and morphological classification, we sampled 138 accessions: two of $N$. lutea, 112 of $N$. nucifera, 17 of hybrids between $N$. nucifera and $N$. lutea, and seven Japanese cultivars. The 11 selected combinations of amplified fragment length polymorphism (AFLP) primers produced 138 polymorphic loci, and the percentage of polymorphism was $\mathbf{2 8 . 7 \%}$. The unweighted pair group method with arithmetic mean (UPGMA) dendrogram clustered all the accessions into two groups: Group I comprised $N$. lutea and its hybrids with $N$. nucifera; Group II included $N$. nucifera and its hybrids with $N$. lutea and Japanese cultivars. Population structure analysis identified four main clusters: $N$. lutea clustered mainly in $\mathrm{C} 1$, whereas $N$. nucifera clustered in $\mathrm{C2}, \mathrm{C} 3$, and $\mathrm{C} 4$, which was consistent with the UPGMA and principal coordinate analysis results. The Japanese cultivars were related more closely to $\mathrm{N}$. nucifera (genetic similarity coefficient $=0.74)$ than to $N$. lutea $(0.46)$; hence, the Japanese cultivars can be classified as $N$. nucifera . Moreover, rhizome lotuses formed a separate subclade, whereas seed lotuses were interspersed among flower lotuses, which demonstrated that rhizome lotuses were distinct from flower and seed lotuses. Plant size, flower color, and other morphological criteria used commonly to classify lotuses were correlated with genetic variation to a certain extent but not sufficiently for accurate classification. It appears that it is necessary to use both DNA markers and morphological characteristics to classify lotus species and cultivars.
\end{abstract}

Lotus is in the family Nelumbonaceae, which consists of only one genus with two species, Nelumbo nucifera and Nelumbo lutea (Kanazawa et al., 1998; Savolainen and Chase, 2003). Nelumbo nucifera is found throughout Asia and Australia.

Received for publication 14 Apr. 2011. Accepted for publication 5 July 2011. This work was supported by the National Natural Science Foundation of China (30671474).

We thank Liming $\mathrm{Xu}$ and Jiarong Zhao for their kind help in the experimental sampling and the analysis of morphological traits.

${ }^{1}$ These two authors contributed equally to this work.

${ }^{2}$ Corresponding author. E-mail: liuyanling@wbgcas.cn.
In China, $N$. nucifera is distributed on both sides of the major freshwater lakes in the valleys of the Yangtze River, Yellow River, and Pearl River. Nelumbo lutea is distributed across North America and northern South America but grows mainly in the eastern and central United States (Borsch and Wilhelm, 1994). Although these two species differ in external morphology such as plant size, leaf shape, petal shape, and color, as a result of their geographical isolation, they share the same number of chromosomes $(2 n=16)$ and the similar karyotype and can be hybridized easily. It has been proposed that $N$. lutea should be considered a subspecies of $N$. nucifera (Huang et al., 1992). However, other scholars consider the two taxa to be 
separate species in the genus Nelumbo (Chen et al., 2008; Han et al., 2007a, 2007b, 2009; Kubo et al., 2009; Li et al., 2010; Tian et al., 2008b).

Nelumbo nucifera is an important ornamental aquatic plant with beautiful flowers and unusual leaves (Ni and Zhao, 1987; Wang and Zhang, 2005). It is also a source of herbal medicine with strong antipyretic, cooling, astringent, and demulcent properties, which can be attributed to alkaloids and flavonoids in the leaves, leaf stems, and rhizomes (Mukherjee et al., 1997; Qian, 2002; Sinha et al., 2000). Nelumbo lutea is a species as magnificent as $N$. nucifera, but it is cultivated less commonly as an ornamental plant. It is considered to be an invasive, difficultto-eradicate weed in its original habitat (Borsch and Wilhelm, 1994; Wiersema, 1997) and probably originally confined to flood plains of major rivers and their tributaries in the east-central United States and carried northward and eastward by aborigines who used the seeds and tubers for food. The rhizome and seeds of $N$. lutea are commonly eaten by Native Americans, and those of $N$. nucifera are still a part of the Oriental diet. In Japan, the lotus has been cultivated as an ornamental and food plant since it was introduced from China 1000 years ago (Masuda et al., 2006). Approximately 350 cultivars of lotus are known in Japan, including more than 100 landraces (Kubo et al., 2009).

In China, the lotus has been cultivated for more than 3000 years, and rich germplasm resources have been generated by artificial hybridization and selection (Ni and Zhao, 1987; Wang and Zhang, 2005). More than 600 lotus cultivars have been recorded in China and have been classified into three main types on the basis of their morphological characteristics and agricultural properties: 1) flower lotus; 2) seed lotus; and 3) rhizome lotus (Wang and Zhang, 2005; Zou et al., 1997). The flower lotus cultivars have been subdivided further on the basis of petal characteristics into several types, which include: 1) few-petaled lotus, with less than 24 petals per flower; 2) double-petaled lotus, in which most of the stamens have been transformed into petals; 3) duplicated-petaled lotus, in which pistils have been transformed into petals or bubbled; 4) versicolor lotus, with red strips or blocks dotted on the white petal; and 5) thousandpetaled lotus, in which the stamens, pistils, and receptacles have all been transformed into petals (Wang and Zhang, 2005). However, such characteristics might not be useful for classification because of their continuous variation and high degree of plasticity in response to changes in environmental conditions. In light of these limitations, further analysis of the genetic differences among lotus cultivars by molecular methods is necessary.

In recent years, the rapid development of molecular marker technologies and DNA fingerprinting analysis has provided new techniques to assess the genetic diversity of plants and animals such as random amplified polymorphic DNA (RAPD), AFLPs, intersimple sequence repeats (ISSRs), and simple sequence repeats (SSRs) (Ge et al., 2005; Oraguzie et al., 2001; Torres-Díaz et al., 2007; Wang et al., 2011). These approaches have also been used to analyze the genetic diversity of the lotus (Chen et al., 2008; Guo et al., 2007; Han et al., 2007a, 2007b, 2009; Kubo et al., 2009; Li et al., 2010; Pan et al., 2007, 2010; Tian et al., 2008a, 2008b) and have revealed rich genetic variation in lotus germplasm. Although AFLP markers are dominant in most cases, they can detect more variation at the whole genome level than ISSR or RAPD markers and are more efficient, because large numbers of loci can be screened readily ( $\mathrm{Na}$ et al., 2009; Portis et al., 2005). At present, only one study that used AFLP markers to evaluate the genetic diversity of rhizome lotuses has been published (Peng et al., 2004). However, the limited number of AFLP markers (two pairs) and lotus accessions (12 rhizome lotuses) that were used was not sufficient to assess the genetic variation of the lotus.

In the study reported here, 11 AFLP primer pairs were selected to evaluate the genetic diversity and relationships among 138 lotus accessions. The accessions represented a large collection of genotypes of the two species ( $N$. lutea and $N$. nucifera): flower lotuses, seed and rhizome cultivars, ancient lotuses, Japanese cultivars, and tropical lotuses. The objectives were to: 1) evaluate the genetic relationship between $N$. nucifera and $N$. lutea; 2) assess the genetic diversity among flower, seed, and rhizome lotuses; and 3) confirm which morphological characteristics can be used in the classification of lotuses.

\section{Materials and Methods}

Plant materials. In total, 138 lotus accessions were used in this study (Table 1): two of $N$. lutea, 112 of $N$. nucifera (76 flower lotuses, nine seed lotuses, 26 rhizome lotuses, and one ancient lotus), 17 of hybrids between $N$. nucifera and $N$. lutea, and seven Japanese cultivars. All accessions have been collected and lodged at Wuhan Botanical Garden, Chinese Academy of Sciences in Wuhan, Hubei Province, China.

AMPLified FRAGMent LENGTH POLYMORPhisM aNALYSIS. Approximately $2 \mathrm{~g}$ of fresh young leaves were harvested from plants and used for the extraction of total genomic DNA in accordance with the cetyltrimethylammonium bromide procedure described by Doyle and Doyle (1990). The quality and quantity of the DNA were checked by agarose gel electrophoresis and ultraviolet spectrophotometry. The DNA solution was diluted to $50 \mathrm{ng} \cdot \mu \mathrm{L}^{-1}$ with $1 \mathrm{~mol} \cdot \mathrm{L}^{-1}$ Tris-EDTA buffer and used as a template in the polymerase chain reaction (PCR) amplification for the AFLP analysis.

The AFLP analysis was performed in accordance with the protocol developed by Vos et al. (1995). Genomic DNA was digested with the restriction enzymes EcoRI and MseI amplified by PCR. The PCR products were separated by electrophoresis on polyacrylamide gels and stained by silver nitrate solution. To improve the efficiency, all 224 possible AFLP primer combinations were used first to amplify 10 representative samples. From the preliminary screening, 11 primer combinations that gave repeatable, clear, and abundant polymorphic bands were selected for the analysis of all 138 accessions. The sequences of the 11 primer combinations selected are listed subsequently:

E01/M04, 5' -GACTGCGTACCAATTCATC-3'/5' -GATGAGTCCT GAGTAACTA-3';

E02/M18, 5' -GACTGCGTACCAATTCAGA-3' /5' -GATGAGTCCT GAGTAACAC-3';

E03/M03, 5'-GACTGCGTACCAATTCACA-3' /5' -GATGAGTCCT GAGTAACTG-3';

E03/M13, 5'-GACTGCGTACCAATTCACA-3'/5' -GATGAGTCCT GAGTAACGC-3';

E03/M18, 5'-GACTGCGTACCAATTCACA-3' /5' -GATGAGTCCT GAGTAACAC-3';

E04/M05, 5'-GACTGCGTACCAATTCACT-3' /5'-GATGAGTCCT GAGTAACAA-3';

E04/M18, 5'-GACTGCGTACCAATTCACT-3'/5' -GATGAGTCCT GAGTAACAC-3'; 
Table 1. Name, collection number in Wuhan Botanic Garden (WBG), origin, morphological characteristics, and amplified fragment length polymorphism (AFLP) group for 138 lotus accessions analyzed by AFLP.

\begin{tabular}{|c|c|c|c|c|c|c|c|c|c|}
\hline \multirow[b]{2}{*}{ No. } & \multirow[b]{2}{*}{ Accession name } & \multirow{2}{*}{$\begin{array}{l}\text { Collection } \\
\text { no. }\end{array}$} & \multirow[b]{2}{*}{ Species or origin } & \multirow{2}{*}{$\begin{array}{l}\text { Sample } \\
\text { type }\end{array}$} & \multirow{2}{*}{$\begin{array}{l}\text { Plant } \\
\text { size }^{z}\end{array}$} & \multirow{2}{*}{$\begin{array}{l}\text { Petal } \\
\text { form }^{\mathrm{y}}\end{array}$} & \multirow{2}{*}{$\begin{array}{l}\text { Flower } \\
\text { color }^{\mathrm{x}}\end{array}$} & \multicolumn{2}{|c|}{ AFLP group } \\
\hline & & & & & & & & Group & $\overline{\text { Subgroup }}$ \\
\hline 1 & Oriole & WBG307 & Hybrid & Flower & Ms & $\mathrm{sD}$ & $\mathrm{Y}$ & $\mathrm{I}$ & Ia1 \\
\hline 2 & Pond Oriole & WBG308 & Hybrid & Flower & Ms & $\mathrm{sD}$ & $\mathrm{Y}$ & I & Ia1 \\
\hline 3 & Jasmine Lotus & WBG205 & Hybrid & Flower & Ms & $\mathrm{F}$ & $\mathrm{Y}$ & I & Ia1 \\
\hline 4 & Golden Lotus & WBG242 & Nelumbo lutea & Flower & $\mathrm{L}$ & $\mathrm{F}$ & $\mathrm{Y}$ & I & Ia1 \\
\hline 5 & Yellow Garden & WBG938 & Hybrid & Flower & Ms & $\mathrm{sD}$ & $\mathrm{Y}$ & I & Ia1 \\
\hline 6 & Fragrant Seeping & WBG213 & Hybrid & Flower & Ms & $\mathrm{sD}$ & $\mathrm{Y}$ & I & Ia1 \\
\hline 7 & Yellow Dancer & WBG117 & Hybrid & Flower & $\mathrm{L}$ & $\mathrm{F}$ & $\mathrm{Y}$ & I & Ia1 \\
\hline 8 & Golden Bird & WBG210 & Hybrid & Flower & Ms & $\mathrm{F}$ & $\mathrm{Y}$ & I & Ia 1 \\
\hline 9 & America Lotus & WBG1042 & N. lutea & Flower & Ms & $\mathrm{F}$ & $\mathrm{Y}$ & I & Ia2 \\
\hline 10 & Learning Dance & WBG1143 & Hybrid & Flower & Ms & $\mathrm{sD}$ & $\mathrm{Y}$ & I & Ia2 \\
\hline 11 & Cool Charming & WBG836 & Hybrid & Flower & Ms & $\mathrm{D}$ & $\mathrm{Y}$ & I & $\mathrm{Ib}$ \\
\hline 12 & Resplendence & WBG807 & Hybrid & Flower & Ms & $\mathrm{D}$ & $\mathrm{Y}$ & I & $\mathrm{Ib}$ \\
\hline 13 & Full of Gold and Jade & WBG907 & Hybrid & Flower & Ms & $\mathrm{D}$ & $\mathrm{Y}$ & I & $\mathrm{Ib}$ \\
\hline 14 & Little Birthday & WBG315 & Nelumbo nucifera & Flower & Ms & $\mathrm{D}$ & $\mathrm{R}$ & II & IIa1 \\
\hline 15 & September Purple & WBG842 & N. nucifera & Flower & Ms & $\mathrm{D}$ & $\mathrm{R}$ & II & IIa1 \\
\hline 16 & Zhuahongcha Bowl & WBG1219 & Japanese cultivar & Flower & Ms & $\mathrm{F}$ & $\mathrm{R}$ & II & IIa1 \\
\hline 17 & Yiliang Thousands Petals & WBG320 & N. nucifera & Flower & $\mathrm{L}$ & $\mathrm{T}$ & $\mathrm{R}$ & II & IIa2 \\
\hline 18 & Thousands Petals & WBG1321 & N. nucifera & Flower & $\mathrm{L}$ & $\mathrm{T}$ & $\mathrm{R}$ & II & IIa2 \\
\hline 19 & Pink Double Palace & WBG1130 & N. nucifera & Flower & $\mathrm{L}$ & $\mathrm{Du}$ & $\mathrm{R}$ & II & IIa2 \\
\hline 20 & Puzhehei Red Lotus & WBG324 & N. nucifera & Flower & $\mathrm{L}$ & $\mathrm{D}$ & $\mathrm{R}$ & II & $\mathrm{IIa} 2$ \\
\hline 21 & Red Thousand Petals & WBG1133 & N. nucifera & Flower & $\mathrm{L}$ & $\mathrm{D}$ & $\mathrm{R}$ & II & IIa2 \\
\hline 22 & Good Luck Lotus & WBG224 & N. nucifera & Flower & Ms & $\mathrm{D}$ & $\mathrm{R}$ & II & IIa2 \\
\hline 23 & Embroidery Jade & WBG1135 & Japanese cultivar & Flower & Ms & $\mathrm{D}$ & $\mathrm{R}$ & II & IIa2 \\
\hline 24 & Red Peony & WBG1137 & N. nucifera & Flower & Ms & $\mathrm{D}$ & $\mathrm{R}$ & II & IIa2 \\
\hline 25 & Camellia Red & WBG1249 & N. nucifera & Flower & Ms & $\mathrm{D}$ & $\mathrm{R}$ & II & IIa2 \\
\hline 26 & Wan'er Hong & WBG1123 & N. nucifera & Flower & Ms & $\mathrm{D}$ & $\mathrm{R}$ & II & IIa2 \\
\hline 27 & Red River & WBG109 & N. nucifera & Flower & Ms & $\mathrm{D}$ & $\mathrm{R}$ & II & $\mathrm{IIa} 2$ \\
\hline 28 & Red Bowl & WBG1129 & N. nucifera & Flower & Ms & $\mathrm{D}$ & $\mathrm{R}$ & II & IIa2 \\
\hline 29 & Frost Morning Moon & WBG416 & N. nucifera & Flower & Ms & $\mathrm{D}$ & $\mathrm{P}$ & II & IIa2 \\
\hline 30 & Pink Exquisite & WBG532 & N. nucifera & Flower & Ms & $\mathrm{D}$ & $\mathrm{P}$ & II & IIa2 \\
\hline 31 & Tender Face & WBG403 & N. nucifera & Flower & Ms & $\mathrm{D}$ & $\mathrm{P}$ & II & IIa2 \\
\hline 32 & Lushan Red & WBG1125 & Japanese cultivar & Flower & Ms & $\mathrm{D}$ & $\mathrm{R}$ & II & IIa2 \\
\hline 33 & Duplicate-petalled Green & WBG1026 & N. nucifera & Flower & Ms & $\mathrm{Du}$ & W & II & IIa3 \\
\hline 34 & Gardenia Bowl Lotus & WBG418 & N. nucifera & Flower & Ms & $\mathrm{Du}$ & W & II & IIa3 \\
\hline 35 & Brilliant Moon & WBG622 & N. nucifera & Flower & Ms & $\mathrm{D}$ & W & II & IIa3 \\
\hline 36 & Green-White Lotus & WBG732 & N. nucifera & Flower & Ms & $\mathrm{Du}$ & $\mathrm{W}$ & II & IIa3 \\
\hline 37 & A Double Handful Snow & WBG817 & N. nucifera & Flower & Ms & $\mathrm{sD}$ & W & II & IIa3 \\
\hline 38 & $\begin{array}{l}\text { Golden Pearls on Jade } \\
\text { Plate }\end{array}$ & WBG1347 & N. nucifera & Flower & Ms & $\mathrm{F}$ & W & II & IIa3 \\
\hline 39 & Luminescent Pearl & WBG630 & N. nucifera & Flower & Ms & $\mathrm{F}$ & W & II & IIa3 \\
\hline 40 & Bright Moon & WBG1337 & N. nucifera & Flower & Ms & $\mathrm{sD}$ & W & II & IIa3 \\
\hline 41 & Green on Jade Plate & WBG721 & N. nucifera & Flower & Ms & $\mathrm{Du}$ & W & II & IIa3 \\
\hline 42 & Jifei Lian & WBG1213 & Japanese cultivar & Flower & Ms & $\mathrm{F}$ & $\mathrm{R}$ & II & IIa4 \\
\hline 43 & Sparkle & WBG621 & N. nucifera & Flower & Ms & $\mathrm{F}$ & $\mathrm{R}$ & II & $\mathrm{IIa} 4$ \\
\hline 44 & Cherry Lotus & WBG1209 & Japanese cultivar & Flower & Ms & $\mathrm{F}$ & $\mathrm{R}$ & II & IIa4 \\
\hline 45 & $\begin{array}{l}\text { Color of Girl's Face and } \\
\text { Peach Flower }\end{array}$ & WBG710 & N. nucifera & Flower & Ms & $\mathrm{D}$ & V & II & IIa5 \\
\hline 46 & Versicolor & WBG910 & N. nucifera & Flower & Ms & $\mathrm{D}$ & $\mathrm{V}$ & II & IIa5 \\
\hline 47 & Red Lady & WBG935 & N. nucifera & Flower & Ms & $\mathrm{D}$ & $\mathrm{R}$ & II & IIa6 \\
\hline 48 & Rosy Dawn Light & WBG1250 & N. nucifera & Flower & Ms & $\mathrm{D}$ & $\mathrm{R}$ & II & IIa6 \\
\hline 49 & Red Skirt with Gold Embroidery & WBG838 & N. nucifera & Flower & Ms & $\mathrm{D}$ & $\mathrm{R}$ & II & IIa6 \\
\hline 50 & Early Peach-red & WBG524 & N. nucifera & Flower & Ms & $\mathrm{D}$ & $\mathrm{R}$ & II & IIa6 \\
\hline 51 & Table Lotus & WBG1127 & N. nucifera & Flower & Ms & $\mathrm{D}$ & $\mathrm{R}$ & II & IIa6 \\
\hline 52 & Red Stay when Green Faded & WBG824 & N. nucifera & Flower & Ms & $\mathrm{D}$ & $\mathrm{R}$ & II & IIa6 \\
\hline 53 & Autumn Beauty & WBG618 & N. nucifera & Flower & Ms & $\mathrm{D}$ & $\mathrm{R}$ & II & IIa6 \\
\hline 54 & Yangcheng Bowl & WBG1016 & N. nucifera & Flower & Ms & $\mathrm{D}$ & $\mathrm{R}$ & II & IIa6 \\
\hline
\end{tabular}




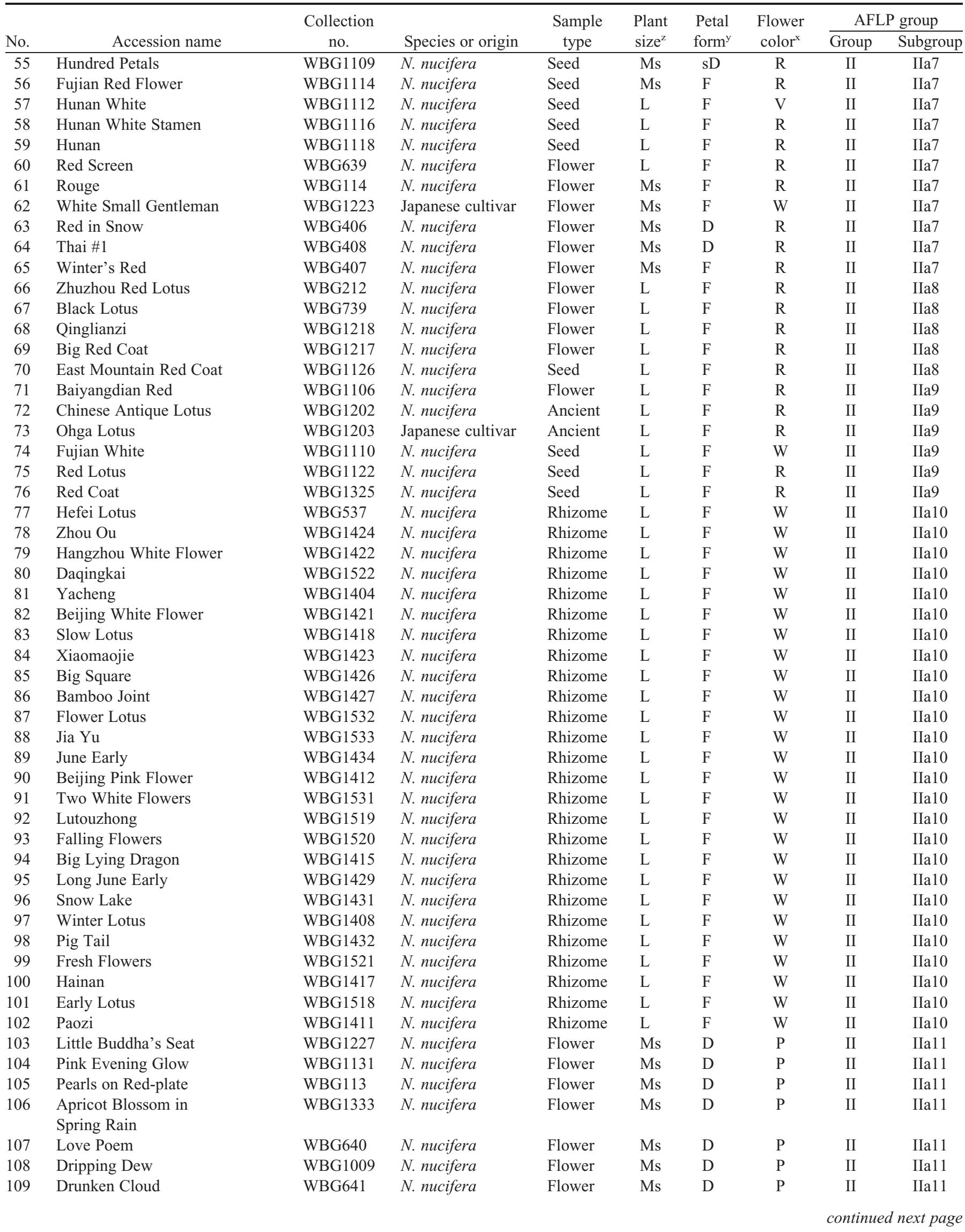


Table 1. Continued.

\begin{tabular}{|c|c|c|c|c|c|c|c|c|c|}
\hline \multirow[b]{2}{*}{ No. } & \multirow[b]{2}{*}{ Accession name } & \multirow{2}{*}{$\begin{array}{c}\text { Collection } \\
\text { no. }\end{array}$} & \multirow[b]{2}{*}{ Species or origin } & \multirow{2}{*}{$\begin{array}{c}\text { Sample } \\
\text { type }\end{array}$} & \multirow{2}{*}{$\begin{array}{l}\text { Plant } \\
\text { size }^{z}\end{array}$} & \multirow{2}{*}{$\begin{array}{l}\text { Petal } \\
\text { form }^{y}\end{array}$} & \multirow{2}{*}{$\begin{array}{l}\text { Flower } \\
\text { color }^{\mathrm{x}}\end{array}$} & \multicolumn{2}{|c|}{ AFLP group } \\
\hline & & & & & & & & Group & Subgroup \\
\hline$\overline{110}$ & Little Drunken Fairy & WBG733 & N. nucifera & Flower & Ms & $\mathrm{D}$ & $\mathrm{P}$ & II & IIa11 \\
\hline 111 & Chrysanthemum Pot & WBG534 & N. nucifera & Flower & Ms & $\mathrm{D}$ & $P$ & II & IIa11 \\
\hline 113 & Drunken Beauty & WBG116 & $N$. nucifera & Flower & Ms & $\mathrm{D}$ & $\mathrm{P}$ & II & IIa12 \\
\hline 114 & Pingshan Lotus & WBG734 & $N$. nucifera & Flower & Ms & $\mathrm{D}$ & $P$ & II & IIa12 \\
\hline 117 & The Sound of Autumn & WBG830 & N. nucifera & Flower & Ms & $\mathrm{D}$ & $\mathrm{R}$ & II & IIa13 \\
\hline 118 & Red Rolling Silk Ball & WBG1003 & N. nucifera & Flower & Ms & $\mathrm{Du}$ & $\mathrm{R}$ & II & IIa13 \\
\hline 119 & Fair Dawn & WBG609 & N. nucifera & Flower & Ms & $\mathrm{sD}$ & $\mathrm{R}$ & II & IIa13 \\
\hline 120 & Full Happiness & WBG610 & N. nucifera & Flower & Ms & $\mathrm{sD}$ & $\mathrm{R}$ & II & IIa13 \\
\hline 121 & Little Beauty & WBG631 & $N$. nucifera & Flower & Ms & $\mathrm{D}$ & $\mathrm{R}$ & II & IIa13 \\
\hline 122 & Poem of Autumn & WBG724 & $N$. nucifera & Flower & Ms & $\mathrm{Du}$ & $\mathrm{R}$ & II & IIa13 \\
\hline 126 & Pearls in Green House & WBG708 & N. nucifera & Flower & Ms & $\mathrm{Du}$ & $\mathrm{R}$ & II & IIa13 \\
\hline 127 & Red Exquisite & WBG302 & N. nucifera & Flower & Ms & $\mathrm{Du}$ & $\mathrm{R}$ & II & IIa13 \\
\hline 128 & Rose Red Duplicate & WBG1619 & $N$. nucifera & Flower & Ms & $\mathrm{Du}$ & $\mathrm{R}$ & II & IIa13 \\
\hline 129 & Spring Hope & WBG812 & N. nucifera & Flower & Ms & $\mathrm{sD}$ & $\mathrm{P}$ & II & IIa14 \\
\hline 130 & Pink Tower & WBG102 & N. nucifera & Flower & Ms & $\mathrm{D}$ & $\mathrm{P}$ & II & IIa14 \\
\hline 131 & Pure Heart & WBG901 & $N$. nucifera & Flower & Ms & $\mathrm{sD}$ & W & II & IIa15 \\
\hline 132 & Little Antelope & WBG912 & $N$. nucifera & Flower & Ms & $\mathrm{sD}$ & W & II & IIa15 \\
\hline 133 & Little Oriole & WBG918 & Hybrid & Flower & Ms & $\mathrm{sD}$ & $\mathrm{Y}$ & II & $\mathrm{IIb}$ \\
\hline 134 & Golden Sun & WBG917 & Hybrid & Flower & Ms & $\mathrm{D}$ & $\mathrm{Y}$ & II & $\mathrm{IIb}$ \\
\hline 135 & Colorful Glow & WBG937 & Hybrid & Flower & Ms & $\mathrm{D}$ & $\mathrm{V}$ & II & $\mathrm{IIb}$ \\
\hline 136 & Orange of Loquat & WBG342 & Hybrid & Flower & Ms & $\mathrm{D}$ & $\mathrm{V}$ & II & $\mathrm{IIb}$ \\
\hline 137 & Charming Lips & WBG332 & Hybrid & Flower & Ms & $\mathrm{Du}$ & $\mathrm{V}$ & II & $\mathrm{IIb}$ \\
\hline
\end{tabular}

${ }^{\mathrm{z}} \mathrm{Ms}=$ medium to small plant; $\mathrm{L}=$ large plant.

${ }^{\mathrm{y}} \mathrm{F}=$ few petals; $\mathrm{sD}=$ semidouble petals; $\mathrm{D}=$ double petals with most of the stamens transformed into petals; Du $=$ duplicated petals with stamens and pistils transformed into petals or bubbled; $\mathrm{T}=$ thousand petals with stamens, pistils, and receptacles all transformed into petals.

${ }^{\mathrm{x}} \mathrm{Y}=$ yellow flower; $\mathrm{W}=$ white flower; $\mathrm{R}=$ red flower; $\mathrm{P}=$ pink flower; $\mathrm{V}=$ versicolor flower.

E05/M02, 5'-GACTGCGTACCAATTCAAG-3'/5'-GATGAGTCCT GAGTAACCA-3';

E05/M16, 5'-GACTGCGTACCAATTCAAG-3'/5'-GATGAGTCCT GAGTAACCC-3';

E06/M05, 5'-GACTGCGTACCAATTCAGT-3'/5'-GATGAGTCCT GAGTAACAA-3';

E07/M04, 5'-GACTGCGTACCAATTCAAC-3'/5'-GATGAGTCCT GAGTAACTA-3'.

Statistical data analysis. The AFLP bands at a given locus were scored as 1 (present) or 0 (absent) to create a binary matrix set (bands of the same size were considered to belong to the same locus).

Genetic similarity among all accessions was calculated by using NTSYS-pc version 2.1 software (Rohlf, 2000) on the basis of the simple matching coefficient and then a dendrogram was constructed by UPGMA. The binary data were also subjected to principal coordinate analysis (PCA) using EIGEN modules.

The population structure of the lotus accessions was estimated on the basis of the AFLP data set using the software STRUCTURE Version 2.2 (Pritchard et al., 2000). The assumed number of populations $(K)$ was varied between two and 10. Five runs for each $K$ value were conducted using an admixture model and correlated allele frequencies. A burn-in period of 10,000 followed by 50,000 iterations was used for clustering of populations.

\section{Results}

GENETIC DIVERSITY OF LOTUS ACCESSIONS. Eleven AFLP primer combinations were selected from all the combinations of AFLP primers and yielded abundant polymorphic markers among the 138 lotus accessions. The scored DNA fragments ranged in size from 75 to $300 \mathrm{bp}$. In total, 481 bands were obtained from PCR amplification using the 11 AFLP primer combinations, of which 138 (28.7\%) were polymorphic across all samples. The number of polymorphic loci per primer combination varied from five to 21 with a mean of 13 .

Genetic similarity among the lotus accessions was estimated using NTSYS-pc 2.1. The genetic similarity coefficient among the accessions varied from 0.21 to 0.99 with an average of 0.68 (data not shown). To further assess the genetic similarity of different kinds of lotus accessions used in this study, the material was divided into seven groups on the basis of origin and use: $N$. nucifera, $N$. lutea, hybrid between $N$. nucifera and $N$. lutea, Japanese cultivar, flower lotus, seed lotus, and rhizome lotus (Table 2). The similarity coefficient between $N$. nucifera and $N$. lutea $(0.42)$ was much lower than those within these two 
Table 2. Genetic similarity coefficients of lotus accessions on the basis of amplified fragment length polymorphism analysis. ${ }^{z}$

\begin{tabular}{|c|c|c|c|c|c|c|c|}
\hline & Nelumbo nucifera & Nelumbo lutea & Hybrid & Japanese cultivar & Flower lotus & Seed lotus & Rhizome lotus \\
\hline N. nucifera & 0.74 & & & & & & \\
\hline N. lutea & 0.42 & 0.68 & & & & & \\
\hline Hybrid & 0.51 & 0.61 & 0.59 & & & & \\
\hline Flower lotus & 0.69 & 0.55 & 0.53 & 0.69 & 0.66 & & \\
\hline Seed lotus & 0.75 & 0.41 & 0.52 & 0.74 & 0.69 & 0.76 & \\
\hline Rhizome lotus & 0.79 & 0.37 & 0.50 & 0.71 & 0.69 & 0.80 & 0.90 \\
\hline
\end{tabular}

${ }^{\mathrm{z}}$ Numbers on the diagonal are the average coefficients of the lotus accessions within each group; the numbers below the diagonal are the average coefficients between the groups.

groups ( 0.74 and 0.68 , respectively). The coefficient within the hybrid accessions (0.59) was the lowest for all intragroup similarity. Moreover, the coefficient between the hybrid accessions and those of $N$. nucifera $(0.51)$ was lower than the coefficient between the hybrid accessions and those of $N$. lutea $(0.61)$.

The mean similarity coefficient within the Japanese cultivars (0.74) was the same as that between the Japanese cultivars and the accessions of $N$. nucifera. This value was much higher than the coefficient between the Japanese cultivars and $N$. lutea $(0.46)$ and represented that the Japanese cultivars were related more closely to $N$. nucifera than to $N$. lutea. The coefficient within the groups of rhizome lotus cultivars was 0.90 , which was greater than those within the groups of flower lotuses $(0.66)$ or seed lotuses (0.76) and indicated that the genetic relationships among the cultivars of rhizome lotuses were closer than those among the flower and seed lotuses.

Cluster analysis. From the UPGMA analysis of the AFLP data, a dendrogram was constructed for the 138 lotus accessions (Fig. 1). The accessions were all divided into two groups (Groups I and II) with a similarity coefficient of 0.45 . The 13 accessions in Group I corresponded to $N$. lutea and hybrids of $N$. lutea with $N$. nucifera and were all flower lotuses with yellow petals. Group II was composed of accessions of $N$. nucifera, hybrids of $N$. nucifera with $N$. lutea, and Japanese cultivars. The cultivars in this group were a mixture of flower, seed, and rhizome lotuses. Flower color was diverse, from white to red, and flower type varied in regard to the number of petals.

Group I was divided further into two subgroups (Ia and $\mathrm{Ib}$ ) with a similarity coefficient of $\approx 0.58$. Group Ia consisted of 10 accessions: the two $N$. lutea accessions ('Golden Lotus' and 'America Lotus') and their hybrids with $N$. nucifera. Group Ib (No. 11-13) included the cultivar Cool Charming and its hybrid progenies with $N$. nucifera. The origin of 'Cool Charming' is unknown, but it was found here to have a close genetic relationship with hybrids between $N$. lutea and $N$. nucifera; thus, it might itself be a hybrid. 'Golden Lotus' (No. 4) of $N$. lute $a$ and its hybrids (No. 1 to -3 and 5 to 8 ) were clustered in Group Ia1, whereas 'America Lotus' (No. 9) and its hybrid (No. 10) formed Group Ia2.

Group II could also be subdivided into two subgroups (IIa and IIb) with a similarity coefficient of 0.62 . One hundred nineteen accessions (No. 14 to 132), which included all the $N$. nucifera and Japanese cultivars, were clustered in Group IIa. Flower color in this subgroup was mainly white, pink, or red. The six accessions in Group IIb were hybrids between $N$. lutea and $N$. nucifera and had yellow or versicolor flowers. Two of the hybrids, 'Little Oriole' (No. 133) and 'Golden Sun' (No. 134), which both had yellow petals, were the progeny of 'Golden Lotus', but the parents of the other four hybrids were unknown. Group IIa comprised 15 subclusters (IIa1 to IIa15), and most of the accessions gathering in each group had a consistent overall plant size and flower color (Table 1). The accessions in Groups IIa8 and IIa9 (flower and seed lotuses) and IIa10 (rhizome lotus) shared a common feature of large-sized plant. The flower and seed lotuses in these groups mainly had red petals, whereas the rhizome lotuses mainly had white petals. Medium to small-sized accessions were clustered in other subgroups, and the clustering was consistent with petal color.

The PCA revealed a similar grouping of the accessions as the dendrogram constructed by UPGMA (Fig. 2). For instance, in the dendrogram, accessions 1 to 13 and 133 to 138 , which corresponded to $N$. lutea and hybrids between $N$. lutea and $N$. nucifera, were located in Groups I and IIb, respectively, and were genetically very different from $N$. nucifera (Group IIa). These $N$. lutea and hybrid accessions were also separated from N. nucifera by PCA.

Population STRUCTURe OF LOTUS ACCESSIONS. The results are shown in Figure 3. The number of clusters, $K$ (which corresponds to the number of populations), was inferred to be four on the basis of likelihood values. Lotus accessions 1 to 13 belonged to cluster $\mathrm{C}$ 1, which was consistent with their clustering into Group I in the dendrogram constructed by UPGMA and the results of the PCA. Accessions 17 to 65 were clustered mainly in C2. Cluster C3 contained mainly accessions 66 to 102. Cluster C4 included accessions 115 to 127 . The other accessions (No. 128 to 138) belonged to multiple clusters, which indicated their complex genetic composition. These estimates are quite similar to the results obtained with the UPGMA cluster analysis.

The two accessions of $N$. lutea, 'Golden Lotus' (No. 4) and 'America Lotus' (No. 9), were consistently in cluster C1. The ancient lotuses 'Chinese Antique Lotus' (No. 72) and 'Ohga Lotus' (No. 73) were consistently in cluster C3. The hybrids and other Japanese cultivars were distributed through multiple clusters. The seed lotuses were found in cluster $\mathrm{C} 2$ or $\mathrm{C} 3$, and the rhizome lotuses were distributed in $\mathrm{C} 3$, which indicated that they were genetically uniform. In contrast, the flower lotuses showed up in multiple clusters.

\section{Discussion}

The genetic Relationship Between $N$. NUCIFERA AND $\boldsymbol{N}$. LUTEA. Lotuses are basal eudicots and have a longer evolutionary history than most flowering plants. They have accumulated considerable genetic diversity, particularly as a result of the geographical isolation of the two species (Ni and Zhao, 1987; Wang and Zhang, 2005). The 138 lotus accessions that were analyzed in the study were derived from $N$. nucifera and $N$. lutea directly or indirectly through interspecific or intraspecific 


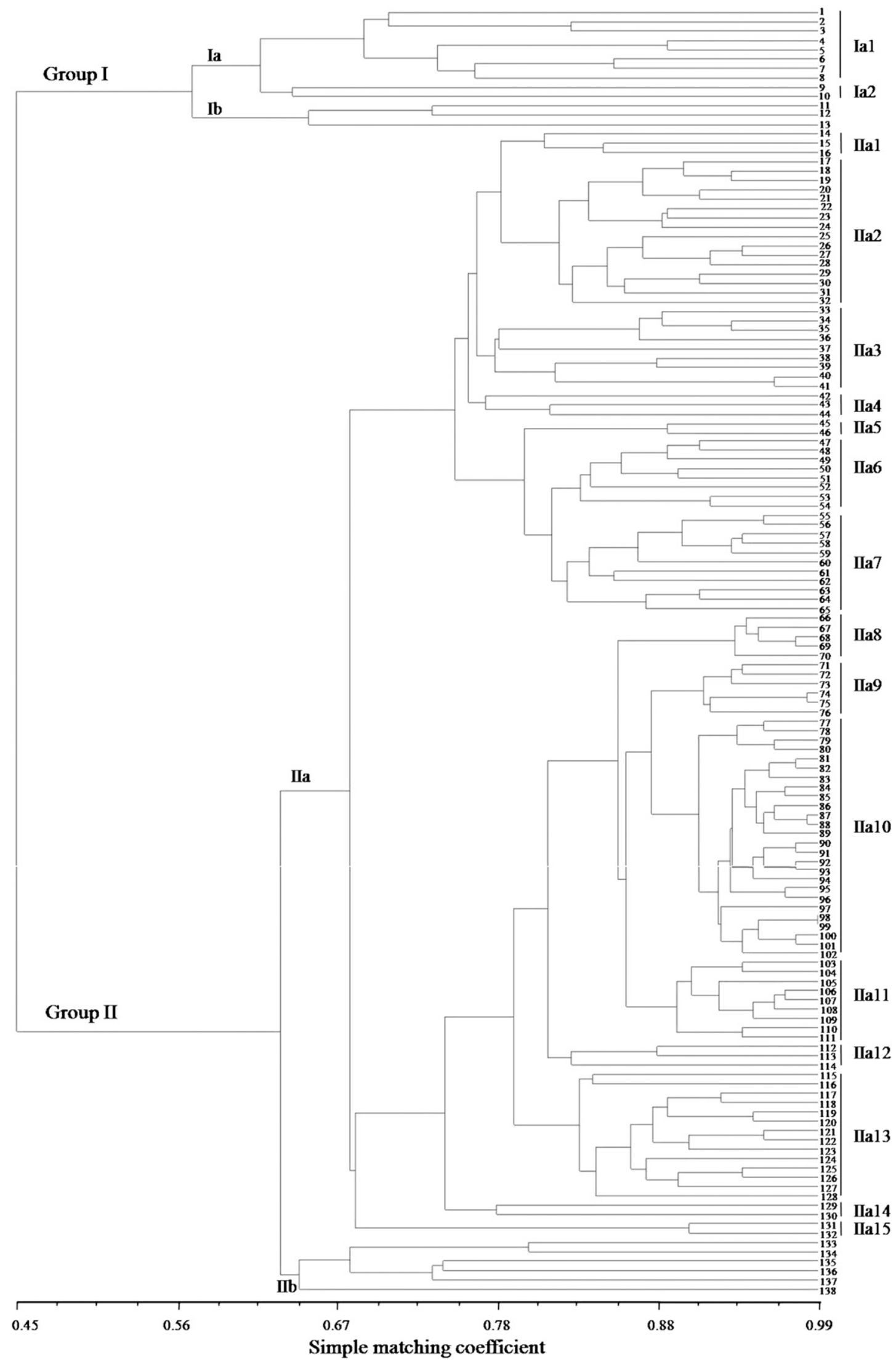

Fig. 1. Dendrogram of 138 lotus accessions obtained by unweighted pair group method with arithmetic mean cluster analysis of data from amplified fragment length polymorphism markers. Simple similarity values are given at the bottom of the dendogram. Numbers on the right of the dendrogram indicate the 138 lotus accessions and correspond with Table 1 . Roman numerals I and II indicate the two groups that were discriminated by a similarity coefficient of 0.45 . Groups Ia and $\mathrm{Ib}$, and IIa and IIb are the subgroups of Groups I and II, respectively. Ia1 to Ia2 and IIa1 to IIa15 are the subclusters within subgroups Ia and IIa, respectively. 


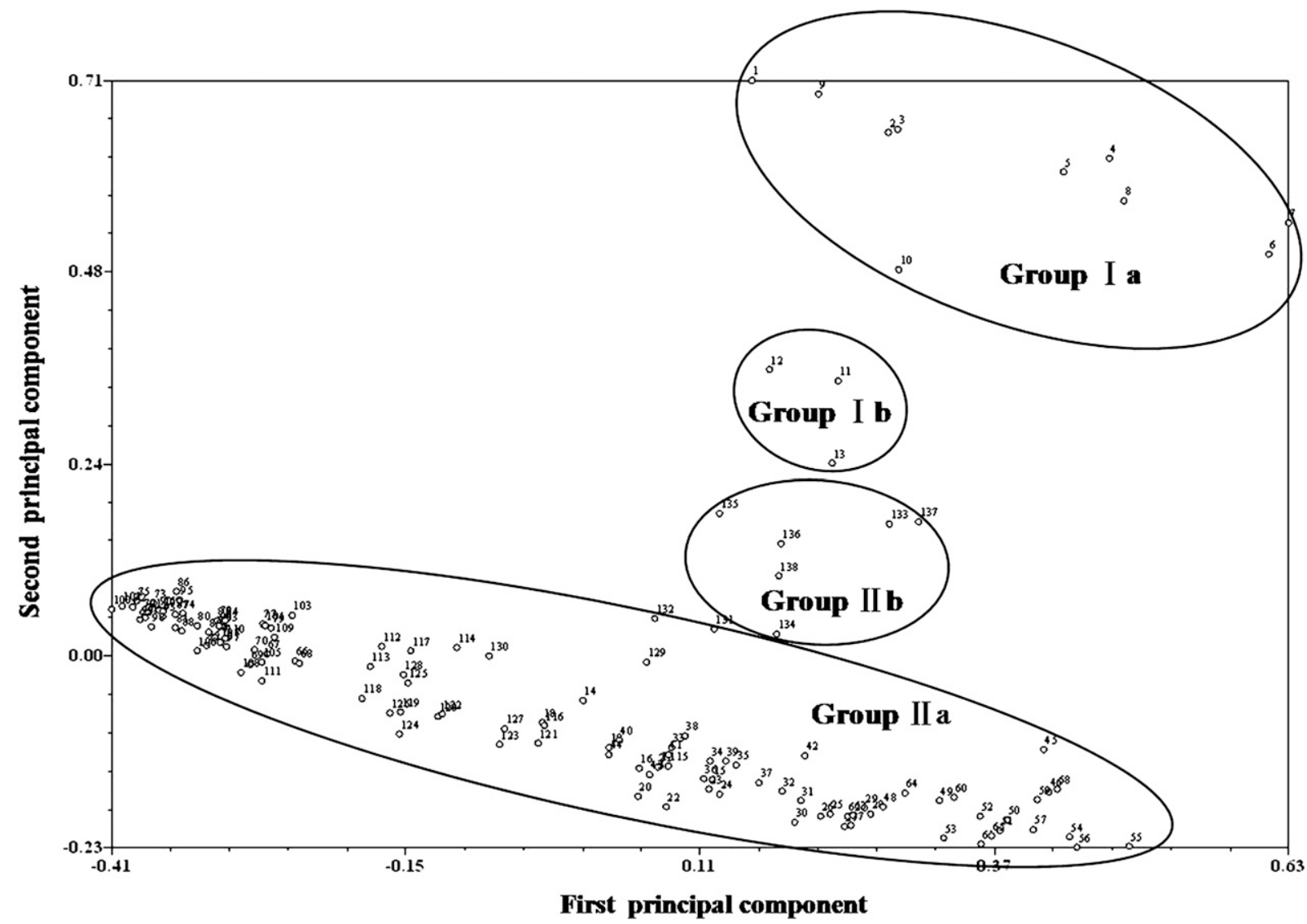

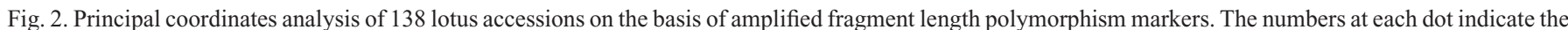
138 lotus accessions and correspond with Table 1. The accessions within the four groups formed are identical to those in Groups Ia, Ib, IIa, and IIb in the dendrogram constructed by unweighted pair group method with arithmetic mean.

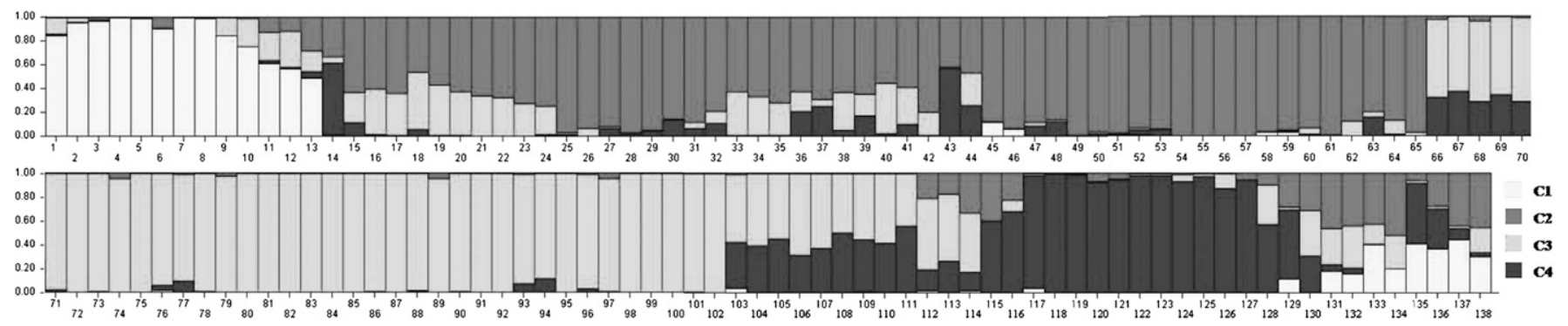

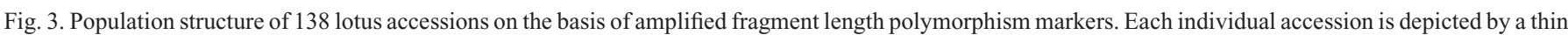
rectangle that is broken into four colored segments that represent the estimated membership fractions of the four clusters (C1, C2, C3, and C4). Numbers under each thin rectangle indicate the 138 lotus accessions and correspond with Table 1.

hybridization. The accessions were divided into two groups [I and II (Fig. 1)]. The two accessions of $N$. lutea were assigned to Group I and thus were separated from the accessions of $N$. nucifera, which were all in Group II. The genetic similarity coefficient between the two species was low [0.42 (Table 2)]. The STRUCTURE analysis demonstrated that $N$. lutea was consistently in cluster $\mathrm{C} 1$ (Fig. 3), whereas the accessions of $N$. nucifera were found in clusters $\mathrm{C} 2, \mathrm{C} 3$, and $\mathrm{C} 4$. These results confirmed that $N$. lutea was genetically distinct from $N$. nucifera and supported the conclusion that $N$. nucifera and $N$. lutea are two separate species in the genus Nelumbo as has been reported previously with different types of molecular marker
(Chen et al., 2008; Han et al., 2007a, 2007b, 2009; Kubo et al., 2009; Li et al., 2010; Tian et al., 2008b). It is likely that the genetic differentiation of $N$. lutea and N. nucifera is the result of long periods of geographical isolation and a lack of gene flow.

Despite their geographical isolation, there are no hybridization barriers between the two separate species and they can be crossed easily (Huang et al., 1992). In recent years, in an attempt to obtain cultivars with yellow flowers, hybridization between $N$. lutea and $N$. nucifera has been practiced extensively. In the current study, 17 hybrids derived from the two species were sampled, and there was a greater number of hybrids with yellow flowers than with versicolor flowers, which 
might be the result of the preference of breeders for cultivars with yellow petals. On the basis of morphological characteristics, Wang and Zhang (2005) proposed to classify hybrids of $N$. lute and $N$. nucifera as a single class. However, the 17 hybrids analyzed here were found to be dispersed between both groups of the genetic dendrogram (Table 1; Fig. 1). The differences between the hybrids in the two groups might be caused by different genetic compositions. The major genetic contribution to hybrids in Group I would appear to be derived from N. lutea, whereas the major genetic contribution to hybrids in Group II appeared to be derived from $N$. nucifera; this difference was confirmed by the STRUCTURE results. The hybrids in Group I were consistently in cluster C1, whereas those in Group II had a more complex genetic composition and were distributed among clusters $\mathrm{C} 1, \mathrm{C} 2, \mathrm{C} 3$, and $\mathrm{C} 4$ (Fig. 3). This result indicates that the selection and backcrosses were made to either $N$. lutea to give the hybrids found in Group I or $N$. nucifera to give the hybrids found in Group II.

THE GENETIC RELATIONSHIP BETWEEN LOTUS CULTIVARS FROM China AND JAPAN. In this study, seven Japanese cultivars (which included the ancient lotus 'Ohga Lotus') were analyzed to evaluate their genetic relationship with $N$. nucifera and $N$. lutea. These cultivars were all clustered in Group IIa and were scattered among the $N$. nucifera accessions from China (Figs. 1 and 2). The coefficient of genetic similarity between the Japanese cultivars and $N$. nucifera was much higher than that between the Japanese cultivars and $N$. lutea $[0.74$ versus 0.46 (Table 2)], which suggested that the Japanese cultivars probably belong to $N$. nucifera. This result was supported by previous studies that used internal transcribed spacer, ISSR, and SSR markers (Han et al., 2007a; Kubo et al., 2009) and is consistent with the geographical distribution of $N$. nucifera.

The ancient Chinese lotus 'Chinese Antique Lotus' (No. 72) and the Japanese cultivar Ohga Lotus (No. 73) both originated from the seeds of ancient lotuses that had been buried underground for more than 1000 years and were discovered at Pulandian, Liaoning Province, China, and Chiba-ken, Japan, in 1951, respectively (Kanazawa et al., 1998; Wang and Zhang, 2005). Despite their different geographical locations, the two ancient lotuses had similar morphological features such as large plant size, few petals and red flowers, and similar genetic compositions. In two previous studies that used RFLP and SSR markers, these ancient lotuses were found to be located close to each other in the phylogenetic trees that were generated with high bootstrap values, $78 \%$ and $96.6 \%$, respectively (Kanazawa et al., 1998; Kubo et al., 2009). In the present study, the genetic similarity coefficient between them was 0.96 (data not shown), and both were in cluster C3 (Fig. 3). These results are supported by available historical evidence that lotuses were imported from China to Japan in ancient times (Masuda et al., 2006) and confirms that Japanese cultivars should be classified as $N$. nucifera (Han et al., 2007a; Kanazawa et al., 1998; Kubo et al., 2009).

GENETIC RELATIONSHIPS AMONG FLOWER, SEED, AND RHIZOME LOTUSES. Through traditional artificial selection and agricultural use, three categories of $N$. nucifera have been established: flower, seed, and rhizome lotuses (Wang and Zhang, 2005; Zou et al., 1997). This classification is based mainly on morphological traits. In the current study, we analyzed the genetic relationships within and among the three groups. The coefficient of genetic similarity was highest within the rhizome lotuses (0.90) as compared with the flower and seed lotuses $[0.66$ and 0.76 , respectively (Table 2 ) $]$. Rhizome lotus cultivars that were analyzed (No. 77 to 102) clustered together and formed a separate subclade, Group IIa10 (Table 1; Fig. 1), which indicated the existence of a close genetic relationship among rhizome lotuses and a distinct genetic background from flower and seed lotuses. Moreover, the genetic backgrounds of the rhizome lotuses were relatively homogeneous and clustered in C3 (Fig. 3), which might be explained by the fact that rhizome lotus cultivars are mostly bred and propagated by asexual reproduction, through underground rhizomes, to fix valuable traits. They have the common characteristics of thick and edible underground rhizome. Consequently, the presence of thick and edible rhizomes is most likely to be used as a morphological characteristic for classification.

There was no obvious distinction between the flower and seed lotus cultivars. Seed lotus cultivars were interspersed among the cultivars of flower lotuses, which indicated that seed lotuses were phylogenetically close to flower lotuses. This finding was confirmed by the PCA and STRUCTURE results (Figs. 2 and 3). Flower and seed lotuses might share a common origin and might have been selected from similar, if not the same, gene pools. Many flower and seed lotus cultivars have been hybridized with each other. Any lotus accession whose flowers are of ornamental value can be classified as a flower lotus. Seed lotuses have beautiful flowers with well-developed pistils and stamens and can also produce abundant seeds. Seed lotuses can be classified separately from flower lotuses provided that they give high yield with fine-quality seed. So seed lotus can be considered as a special type of flower lotus. This might explain why flower and seed lotuses were not distinguished genetically from each other.

Zhang and Wang (2006) found that lotuses could be divided into two ecotypes, namely temperate and tropical cultivars. The former typically have an annual growth cycle, an enlarged rhizome that is dormant during the winter, and include flower, seed, and rhizome lotuses that are cultivated in inland China. The latter keep growing throughout the year, have a thin rhizome, and include lotuses that are cultivated in southern China and southeast Asia. We analyzed three tropical lotuses (No. 63 to 65 ). These accessions bloom quite freely during the cold months of the year, but their underground rhizome does not become enlarged even in Wuhan (south-central region). The tropical accessions were related more closely to $N$. nucifera than to $N$. lutea and were interspersed with the flower and seed lotuses that are cultivated in inland China [in Group IIa7 (Figs. 1 and 3)]. The results suggest that the three tropical lotuses belong to $N$. nucifera. On the basis of morphological characteristics and genetic analysis, our results supported the two ecotypes proposed by Zhang and Wang (2006).

The CORRELATION Between Genetic Classification AND MORPHOLOGICAL CHARACTERISTICS. In China, lotus cultivars have been classified mainly on the basis of morphological characteristics such as plant size, flower type and color, leaf shape, and color (Wang and Zhang, 2005; Zou et al., 1997), especially flower lotuses. Plant size has been considered to be an important feature in lotus classification. In the present study, the accessions were classified in general into small to medium and large plants (Table 1). For lotuses in Group I, namely $N$. lutea and its hybrids with $N$. nucifera, plant size was small to medium in general. Nelumbo lutea grows poorly in Wuhan, and most of the hybrids that were bred from this species were not vigorous. In Group II, plant size was correlated with the subgroups in the phylogenetic tree to some extent. Most of 
the large-sized cultivars were in Groups IIa8, IIa9, and IIa10, whereas small to medium-sized cultivars were located in other subgroups. However, given that plant size is controlled by multiple genes and is also affected by environmental conditions, it might not be appropriate to use plant size as a basis for cultivar classification.

In most cases, morphological classification is based on flower characteristics (e.g., color and number of petals and size and shape of flowers). We detected a correlation between petal color and genetic relationships. The cultivars with yellow petals were clustered mainly in Group I (N. lutea and its hybrids with $N$. nucifera). In Group II, the partitioning of the subgroups was consistent with flower color. However, petal number did not correlate strongly with genetic variation. For example, doublepetaled lotuses were distributed throughout the dendrogram.

In summary, morphological traits such as plant size and petal color were correlated to some degree with genetic background but not sufficiently to allow lotuses to be classified accurately on the basis of these traits. DNA markers were more informative and accurate in assessing genetic diversity and relationships among lotus accessions. Therefore, it is necessary to use both DNA markers and morphological characteristics to classify lotuses.

\section{Conclusions}

The results confirmed the significant genetic differences between $N$. lutea and $N$. nucifera; this is most likely the result of geographical isolation. The Japanese lotus cultivars had a very close genetic relationship with $N$. nucifera cultivated in China and thus could be classified as $N$. nucifera. Rhizome lotus cultivars were separated genetically from flower and seed lotuses, perhaps as a result of their vegetative propagation by rhizome and their selection on the basis of rhizome characteristics. Although plant size and petal color correlated to some degree with genetic variation, as assessed by DNA markers, morphological traits alone are not adequate for the classification of lotuses.

\section{Literature Cited}

Borsch, T. and B. Wilhelm. 1994. Classification and distribution of the genus Nelumbo Adans (Nelumbonaceae). Beitrage zur Biologie der Pflanzen 68:421-450.

Chen, Y.Y., R.C. Zhou, X.C. Lin, K.Q. Wu, X.E. Qian, and S.Z. Huang. 2008. ISSR analysis of genetic diversity in sacred lotus cultivars. Aquat. Bot. 89:311-316.

Doyle, J.L. and J.J. Doyle. 1990. Isolation of plant DNA from fresh tissue. Focus 12:13-15.

Ge, X.J., Y. Yu, Y.M. Yuan, H.W. Huang, and C. Yan. 2005. Genetic diversity and geographic differentiation in endangered Ammopiptanthus (Leguminosae) populations in desert regions of northwest China as revealed by ISSR analysis. Ann. Bot. (Lond.) 95:843-851.

Guo, H.B., S. Li, J. Peng, and W. Ke. 2007. Genetic diversity of Nelumbo accessions revealed by RAPD. Genet. Resources Crop Evol. 54:741-748.

Han, Y.C., C.Z. Teng, F.H. Chang, G.W. Robert, M.Q. Zhou, Z.L. Hu, and Y.C. Song. 2007a. Analyses of genetic relationships in Nelumbo nucifera using nuclear ribosomal ITS sequence data, ISSR and RAPD markers. Aquat. Bot. 87:141-146.

Han, Y.C., C.Z. Teng, G. Wahiti, M.Q. Zhou, Z.L. Hu, and Y.C. Song. 2009. Mating system and genetic diversity in natural populations of Nelumbo nucifera (Nelumbonaceae) detected by ISSR markers. Plant Syst. Evol. 277:13-20.

Han, Y.C., C.Z. Teng, S. Zhong, M.Q. Zhou, Z.L. Hu, and Y.C. Song. $2007 \mathrm{~b}$. Genetic variation and clonal diversity in populations of
Nelumbo nucifera (Nelumbonaceae) in central China detected by ISSR markers. Aquat. Bot. 86:69-75.

Huang, X.Q., J.Y. Chen, and G.C. Huang. 1992. Preliminary studies on biosystematical relationship between the two Nelumbo species. Acta Hort. Sinica 19:164-170.

Kanazawa, A., S. Watanabe, T. Nakamoto, N. Tsutsumi, and A. Hirai. 1998. Phylogenetic relationships in the genus Nelumbo based on polymorphism and quantitative variations in mitochondrial DNA. Genes Genet. Syst. 73:39-44.

Kubo, N., M. Hirai, A. Kaneko, D. Tanaka, and K. Kasumi. 2009. Classification and diversity of sacred and American Nelumbo species: The genetic relationships of flowering lotus cultivars in Japan using SSR markers. Plant Genet. Resources 7:260-270.

Li, Z., X. Liu, R.W. Gituru, N. Juntawong, M. Zhou, and L. Chen. 2010. Genetic diversity and classification of Nelumbo germplasm of different origins by RAPD and ISSR analysis. Sci. Hort. 125:724732.

Masuda, J.I., T. Urakawa, Y. Ozaki, and H. Okubo. 2006. Short photoperiod induces dormancy in lotus (Nelumbo nucifera). Ann. Bot. (Lond.) 97:39-45.

Mukherjee, P.K., K. Saha, J. Das, M. Pal, and B.P. Saha. 1997. Studies on the antiinflammatory activity of rhizomes of Nelumbo nucifera. Planta Med. 63:367-369.

Na, A., H.B. Guo, and W.D. Ke. 2009. Genetic variation in rhizome lotus (Nelubmo nucifera Gaertn. ssp. nucifera) germplasm from China assessed by RAPD markers. Agr. Sci. China 8:31-39.

Ni, X.M. and J.R. Zhao. 1987. Chinese lotus. Science Press, Beijing, China.

Oraguzie, N.C., S.E. Gardiner, H.C.M. Basset, M. Stefanati, R.D. Ball, V.G.M. Bus, and A.G. White. 2001. Genetic diversity and relationships in Malus sp. germplasm collections as determined by randomly amplified polymorphic DNA. J. Amer. Soc. Hort. Sci. 126:318-328. Pan, L., Z. Quan, S. Li, H. Liu, X. Huang, W. Ke, and Y. Ding. 2007. Isolation and characterization of microsatellite markers in the sacred lotus (Nelumbo nucifera Gaertn.). Mol. Ecol. Notes 7:1054-1056.

Pan, L., Q. Xia, Z. Quan, H. Liu, W. Ke, and Y. Ding. 2010. Development of novel EST-SSRs from sacred Lotus (Nelumbo nucifera Gaertn) and their utilization for the genetic diversity analysis of $N$. nucifera. J. Hered. 101:71-82.

Peng, Y.L., Y.C. Han, L. Wang, C.Z. Teng, M.Q. Zhou, Z.L. Hu, and Y.C. Song. 2004. Genetic diversity in lotus (Nelumbo) accessions revealed by AFLP technique. Mol. Plant Breed. 2:823-827.

Portis, E., L. Barchi, A. Acquadro, J.I. Macua, and S. Lanteri. 2005. Genetic diversity assessment in cultivated cardoon by AFLP (amplified fragment length polymorphism) and microsatellite markers. Plant Breed. 124:299-304.

Pritchard, J.K., M. Stephens, and P. Donnelly. 2000. Inference of population structure using multilocus genotype data. Genetics 155:945-959.

Qian, J.Q. 2002. Cardiovascular pharmacological effects of bisbenzylisoquinoline alkaloid derivatives. Acta Pharmacol. Sin. 23:10861092.

Rohlf, F.J. 2000. NTSYS-pc: Numerical taxonomy and multivariate analysis system, Version 2.1. Exeter Software, Setauket, NY.

Savolainen, V. and M.W. Chase. 2003. A decade of progress in plant molecular phylogenetics. Trends Genet. 19:717-724.

Sinha, S., P.K. Mukherjee, K. Mukherjee, M. Pal, S.C. Mandal, and B.P. Saha. 2000. Evaluation of antipyretic potential of Nelumbo nucifera stalk extract. Phytother. Res. 14:272-274.

Tian, H.L., X.Q. Chen, J.X. Wang, J.H. Xue, J. Wen, G. Mitchell, and S.L. Zhou. 2008a. Development and characterization of microsatellite loci for lotus (Nelumbo nucifera). Conserv. Genet. 9: 1385-1388.

Tian, H.L., J.H. Xue, J. Wen, G. Mitchell, and S.L. Zhou. 2008 b. Genetic diversity and relationships of lotus (Nelumbo) cultivars based on allozyme and ISSR markers. Sci. Hort. 116:421-429.

Torres-Díaz, C., E. Ruiz, F. González, G. Fuentes, and L.A. Cavieres. 2007. Genetic diversity in Nothofagus alessandrii (Fagaceae), an 
endangered endemic tree species of the coastal Maulino Forest of central Chile. Ann. Bot. (Lond.) 100:75-82.

Vos, P., R. Hogers, M. Bleeker, M. Reijans, T.V.D. Lee, M. Hornes, A. Friters, J. Pot, J. Paleman, M. Kuiper, and M. Zabeau. 1995. AFLP: A new technique for DNA fingerprinting. Nucleic Acids Res. 23:44074414.

Wang, Q.C. and X.Y. Zhang. 2005. Pictures and explanation of Chinese lotus species. China Forestry Publishing House, Beijing, China.

Wang, X., P.A. Wadl, C. Pounders, R.N. Trigiano, R.I. Cabrera, B.E. Scheffler, M. Pooler, and T.A. Rinehart. 2011. Evaluation of genetic diversity and pedigree within crapemyrtle cultivars using simple sequence repeat markers. J. Amer. Soc. Hort. Sci. 136:116128.

Wiersema, J.H. 1997. Nelumboanaceae. Flora of North America. Vol. 3. 5 July 2011.<http://www.efloras.org/florataxon.aspx?flora_id= 1\&taxon_id=233500796>.

Zhang, X.Y. and Q.C. Wang. 2006. Preliminary study of the ecotypes of genetic resources of tropical louts. Landscape Plants 22:82-85.

Zou, X., X. Zhao, and X. Jin. 1997. Sacred lotus in China. Jindun Press, Beijing, China. 